\title{
“O Brasil não pode parar": racismo e desigualdade social na campanha publicitária do governo Bolsonaro
}

\author{
Julio Cesar SANCHES ${ }^{1}$ \\ Raika Julie MOISÉS ${ }^{2}$ \\ Rhayller Peixoto da Costa SOUZA ${ }^{3}$
}

\begin{abstract}
Resumo:
A campanha publicitária “O Brasil não pode parar” foi produzida pelo governo Bolsonaro no ano de 2020 com o intuito de justificar a contrariedade da política estatal brasileira em relação às recomendações dos organismos internacionais, que indicavam a importância do isolamento social no combate à pandemia do covid-19. Expondo a necessidade de crescimento econômico e social, mesmo em tempos de pandemia e crise na saúde pública mundial, a narrativa da peça publicitária convocava as trabalhadoras e trabalhadores brasileiros a continuarem com as atividades laborais. Partindo da análise das representações sociais do trabalho e da identificação dos corpos visibilizados pela campanha, o estudo buscou apontar quais eram os sujeitos sociais que não deveriam parar de trabalhar: pessoas negras subalternizadas. A análise do texto e do contexto do vídeo apontou que o discurso produzido na campanha "O Brasil não pode parar" invocou as dinâmicas do racismo estrutural brasileiro, marcado pela manutenção das desigualdades sociais e pelo desprezo às vidas negras.
\end{abstract}

Palavras-chave: Racismo. Covid-19. Governo Bolsonaro. Desigualdade social.

\section{"Brazil can't stop": racism and social inequality in the advertising campaign of Bolsonaro's government}

\begin{abstract}
:
The advertising campaign "Brazil can't stop" was produced by Bolsonaro's government in 2020 in order to justify the fact that State policies went against the recommendations of international organisms regarding the importance of social distancing to fight the covid-19 pandemic. Exposing the need for economic and social growth, even in times of pandemic and worldwide public healthcare crisis, the narrative of the advertising piece called on brazilian workers to continue with their labour activities. Based on the analysis of the work social representations and the identification of the individuals displayed in the campaign, the work aimed to point out which were the social subjects who should not stop working: subaltern black people. In view of it's analysis of the text and the context of the advertising video, it's appointed that the discourse of the campaign "Brazil can't stop" invoked the dynamics of brazilian structural racism, marked by the maintenance of social inequalities and the contempt for black lives.
\end{abstract}

Keywords: racism, covid-19; Bolsonaro's government; social inequality.

\footnotetext{
1 Doutorando em Comunicação e Cultura da Escola de Comunicação da UFRJ. Professor substituto do IHAC/UFBA. Integrante do NECHS - Núcleo de Estudos em Comunicação, História e Saúde. Bolsista CAPES. E-mail: sanches.julius@gmail.com

${ }^{2}$ Doutoranda em Comunicação e Cultura da Escola de Comunicação da UFRJ. Integrante do NECHS - Núcleo de Estudos em Comunicação, História e Saúde.E-mail: raika.moises@gmail.com

${ }^{3}$ Mestrando em Comunicação e Cultura da Escola de Comunicação da UFRJ. Integrante do NECHS - Núcleo de Estudos em Comunicação, História e Saúde. E-mail: rhayllerpeixoto@gmail.com
} 


\section{"Brasil no puede parar": racismo y desigualdad social en la campaña publicitaria del gobierno de Bolsonaro}

Resumen:

La campaña publicitaria "Brasil no puede parar" fue producida por el gobierno de Bolsonaro en el año 2020 con el objetivo de justificar la contradicción de la política de estado brasileña en relación con las recomendaciones de las organizaciones internacionales, que indicaban la importancia del aislamiento social en la lucha contra la pandemia de covid-19. Exponiendo la necesidad de crecimiento económico y social, incluso en tiempos de pandemia y crisis de salud pública mundial, la narrativa de la pieza publicitaria pedía a las trabajadoras y a los trabajadores brasileños que continuaran con sus actividades laborales. A partir del análisis de las representaciones sociales del trabajo y de la identificación de los cuerpos, objeto esencial de la campaña, se buscó señalar cuáles eran los sujetos sociales que no debían dejar de trabajar: los negros subalternos. El análisis del texto y el contexto del vídeo señaló que el discurso producido en la campaña "Brasil no puede parar" invocó la dinámica del racismo estructural brasileño, marcado por el mantenimiento de las desigualdades sociales y por el desprecio a las vidas negras.

Keywords: Racismo. Covid-19. Gobierno Bolsonaro. Desigualdad social.

\section{Introdução: covid-19 no Brasil}

Em março de 2020, o Estado brasileiro passou a produzir as estratégias de isolamento social provocados pela pandemia de covid-19 no mundo. Nos níveis municipal, estadual e federal, diferentes recomendações foram endereçadas à população brasileira. Essas iniciativas, a priori, faziam parte de um conjunto de recomendações de organismos internacionais de saúde, como a Organização Mundial de Saúde (OMS), visando a proteção das populações diante de uma doença até então desconhecida.

As narrativas produzidas por organizações de saúde pública em todo o mundo apontavam que o isolamento social poderia barrar o aumento de casos de COVID-19 (OMS DIZ..., 2020), possibilitando aos estados nacionais uma proteção da população. Entretanto, o governo federal brasileiro, na contramão das recomendações e protocolos adotados em quase todo o mundo, passou a desenvolver também algumas narrativas que contrariaram os discursos hegemônicos sobre a necessidade do isolamento social. Dentre as várias contradições produzidas pelos discursos do presidente da República, Jair Messias Bolsonaro, a produção de um vídeo institucional convocando a população brasileira a manter as atividades laborais causou grande polêmica.

A campanha publicitária "O Brasil não pode parar" foi encomendada pelo governo Bolsonaro como estratégia de convencimento da população de que a economia brasileira não poderia parar, visto que a crise política, institucional e econômica ainda abatia a sociedade. $\mathrm{O}$ discurso da campanha compactuava com o desejo do governo brasileiro em manter as rotinas trabalhistas no comércio, agricultura e indústria, com o intuito de sustentar a ordem 
econômica, visto que a projeção de crescimento do PIB em 2020 era de 2,3\%, como indicava o estudo das previsões macroeconômicas realizado pelo Instituto de Pesquisa Econômica Aplicada (IPEA) (SOUZA JÚNIOR; CAVALCANTI; LEVY; CARVALHO; MORAES; GARCIA, 2020).

Diante da necessidade de distanciamento social, as rotinas de trabalho seriam afetadas e as projeções econômicas do governo não se realizariam. Por isso, a campanha "O Brasil não pode parar" produzia uma narrativa direcionada às trabalhadoras e trabalhadores brasileiros com o intuito de convencer a população de que a economia brasileira precisava de ajuda e que o Brasil não poderia parar de produzir e consumir, pois os efeitos do isolamento social causariam danos às políticas sociais do governo.

A campanha foi barrada pelo Supremo Tribunal Federal (STF), em uma decisão do ministro Luís Roberto Barroso (VITAL, 2020) sobre a ADPF 669, de 31 de março de 2020, que destacou:

Em momento em que a Organização Mundial de Saúde, o Ministério da Saúde, as mais diversas entidades médicas se manifestam pela necessidade de distanciamento social, uma propaganda do Governo incita a população ao inverso. Trata-se, ademais, de uma campanha "desinformativa": se o Poder Público chama os cidadãos da "Pátria Amada" a voltar ao trabalho, a medida sinaliza que não há uma grave ameaça para a saúde da população e leva cada cidadão a tomar decisões firmadas em bases inverídicas acerca das suas reais condições de segurança e de saúde (BRASIL, 2020, não paginado).

Classificada pelo STF como "desinformativa", a campanha publicitária do governo Bolsonaro destacou um determinado regime de representação que precisa ser investigado. Como considera Hall (2016, p. 31), “a representação conecta o sentido e a linguagem à cultura". Afinal, para quem aquela campanha se dirigia? Tomando esse questionamento como princípio, pretendemos identificar os códigos que foram produzidos pelo vídeo, destacando os modos de endereçamento presentes na peça publicitária "O Brasil não pode parar".

Acreditamos que os discursos verbais e visuais destacados pela campanha publicitária do governo Bolsonaro, produzida no início da quarentena no Brasil, revelam um conjunto de disputas políticas e ideológicas atravessadas pelo texto e pelo contexto da produção do vídeo. Nesse sentido, faz-se necessário compreender o quê e para quem o vídeo se endereça, pondo em relevo os conflitos sociais, econômicos, políticos e culturais que envolvem as dinâmicas da realidade social brasileira. Supomos, sobretudo, que a peça publicitária "O Brasil não pode parar" endereçou à população brasileira um conjunto de códigos sociais marcadamente 
racistas, cujas peças do quebra-cabeça apontam para a existência do racismo estrutural (ALMEIDA, 2019).

\section{Representações sociais do trabalho e raça no Brasil}

Pensar a formação de uma classe trabalhadora no Brasil evoca refletir sua estruturação a partir de representações sociais que buscam integrar a multiplicidade étnica que caracteriza o país. Os papéis sociais de trabalhadores e trabalhadoras no Brasil têm, no entanto, uma particularidade, dada sua formação étnica e o contexto de racialização e de gênero que os permeia.

A herança do período escravocrata, a segregação da população preta e parda das áreas nobres do país e a não realização de políticas públicas a fim de integrar a população negra implicaram que, mesmo com uma adesão do mercado de trabalho a pessoas negras, a vulnerabilidade social não deixa de fazer parte do cotidiano da maioria dos trabalhadores brasileiros, aprisionando-os em "lugares sociais específicos". As representações sociais desses lugares remontam à história e são parte de valores que constituem a dimensão do trabalho no Brasil.

A classe trabalhadora, que também é identificada pelos marcadores de raça e de gênero, possui uma dupla representação social, apresentando não somente categorias dentro da esfera do trabalho, mas de um problema de raça e gênero na divisão social do trabalho. Durante a pandemia de covid-19, em 2020, a flexibilização e paralisação de serviços considerados não essenciais desestabilizou a produção econômica do país, que novamente se volta para as pessoas em situação de vulnerabilidade como resposta. Afinal, quem são os trabalhadores e trabalhadoras mais afetados em períodos de crise no Brasil? Que cor essas pessoas têm e quais suas relações com o Estado?

Almeida (2019) diz que o racismo não é um mero reflexo de estruturas arcaicas que poderiam ser superadas com a modernização, pois a modernização em si é racista. Enquanto o sonho de uma nação europeia povoava a mente de uma elite inconformada, esses modos de enxergar o negro, ao menos no que tange a situações específicas no mundo das representações sociais do trabalho, persistiam (e ainda persistem) no imaginário social brasileiro.

No artigo "Eugenia e coronavírus", Bento entende as novas políticas de exclusão e ocultação de dados de raça e cor durante a pandemia de covid-19 como novas formas de eugenia, onde em um dado momento o descaso se torna proposital ao não evidenciar qual o impacto da pandemia de coronavírus nas vidas de pessoas negras. Segundo Bento, a análise 
racializada dos números demonstra uma desproporção significativa em relação às vítimas brancas. A autora afirma que:

No entanto, o dado cor/raça, fundamental para compreender melhor essa situação, figura como "ignorado" ou mesmo não preenchido em aproximadamente $40 \%$ dos formulários de hospitalizações e óbitos, indicando que a lei não vem sendo cumprida e o Estado não desenvolveu campanhas explicativas sobre a importância dessa informação para a definição de políticas públicas a fim de enfrentar os desafios da pandemia (BENTO, 2020).

A falta de dados escancara os problemas das instituições brasileiras em entender o demarcador racial como importante durante a pandemia, dadas as particularidades da situação. Em junho de 2020, o Consórcio de Veículos de Imprensa denunciou, em uma matéria da Folha de São Paulo, que apenas 8 das 27 unidades federativas forneciam os dados necessários para os dados de raça e cor entre as vítimas (MAIORIA..., 2020). No entanto, apesar do campo jornalístico ter dado atenção especial às demandas raciais em torno da pandemia, compreendese que as representações sociais em torno da população negra indicam que a vulnerabilidade não é um consenso reforçado pela mídia de massa, pelo Estado e pelo empresariado brasileiro.

O entendimento de uma classe trabalhadora racializada passa então a fazer sentido se levarmos em consideração que, segundo o Instituto Brasileiro de Geografia e Estatística (IBGE), 55,8\% dos brasileiros são pretos e pardos, compondo, assim, 54,9\% da força de trabalho. Outros dados indicam que $64,2 \%$ se encontram como desocupados e $66,1 \%$ em empregos subutilizados (NITAHARA, 2019). Os números apontam para uma relação assimétrica da população negra do Brasil, com a distribuição e o exercício de trabalho formal: apesar de maioria, são os que possuem mais dificuldade e menos acesso, sendo os mais prejudicados em um cenário de crise sanitária como a da pandemia de COVID-19.

Pensar no Estado brasileiro como veiculador de mensagens de incentivo à atividade laboral durante a pandemia remonta à sua estruturação histórica e aos artifícios que são utilizados para controlar crises como essa. Isso evidencia um problema social não apenas de acesso ao mercado de trabalho, mas também aos termos em que os mais vulneráveis se submetem a postos de trabalho informais. Em um cenário socioeconômico afetado pela doença, evidencia-se ainda mais a desigualdade social e a dependência da classe trabalhadora negra de intervenções estatais que promovam o bem-estar. O que se percebe, no entanto, é o movimento contrário. Conforme apresenta Almeida (2019, p. 201): 
As necessidades de mudança nos parâmetros de intervenção estatal a fim de retornar à estabilidade econômica e política - e aqui entende-se estabilidade como o funcionamento regular do processo de valorização capitalista sempre resultou em formas renovadas de violências e estratégias de subjugação da população negra.

Os atravessamentos de raça e classe indicam uma valorização da pessoa negra por meio do trabalho sendo reiteradas pela resposta do Estado à pandemia. Em um cenário de crises institucionais que evidencia cada vez mais a desumanização de determinadas pessoas, o trabalho emerge como a chance de promover a igualdade a partir da adesão à equipe que vai finalmente salvar o país da grande crise institucional.

\section{“O Brasil não pode parar": uma análise contextual}

"O Brasil não pode parar” é o lema da campanha encabeçada pelo governo Bolsonaro, cujos códigos e discursos merecem ser analisados. Afinal, para quem aquela campanha era endereçada? E quais são os discursos que permeiam as visualidades presentes no vídeo? Partindo destas questões, analisamos a produção audiovisual da campanha correlacionando-a com o contexto político, econômico e social que fez emergir a peça publicitária, pois acreditamos que o par texto-contexto nos ajuda a compreender o processo comunicacional de circulação de sentido, visto que o contexto social faz parte da constituição dos textos, imagens e representações sociais. Essa concepção está firmada no entendimento de que "o contexto afigura-se aí como o exterior constitutivo do texto. Algo que não apenas atravessa os discursos, mas que lhes dá vida, o que dá dinamicidade à sua materialidade, o que faz dele uma prática justamente" (RIBEIRO; MARTINS; ANTUNES, 2017, p. 3). Por isso, faz-se necessário tratar dos contextos que fortificam os discursos e representações. Vejamos a contextualidade da produção da peça “O Brasil não pode parar".

O presidente da República Jair Messias Bolsonaro ficou mundialmente conhecido como um dos líderes globais que contestou as normas e recomendações sanitárias emitidas pela OMS, repetindo as práticas do presidente estadunidense Donald Trump. No dia 24 de março de 2020, por exemplo, Jair Bolsonaro fez um pronunciamento oficial dirigindo-se à nação brasileira e pedindo o restabelecimento da normalidade social. À época, Jair Bolsonaro disse: 
Nossa vida tem que continuar. Os empregos devem ser mantidos, o sustento das famílias deve ser preservado. Devemos, sim, voltar à normalidade. Algumas poucas autoridades estaduais e municipais devem abandonar o conceito de terra arrasada, a proibição de transportes, o fechamento de comércio e o confinamento em massa (BOLSONARO, 2020).

Ao contrariar os discursos médicos, sanitaristas e científicos sobre a necessidade de atenção com a pandemia de covid-19, o governo Bolsonaro desenvolveu estratégias de questionamento acerca da letalidade da pandemia, informando ao povo que ela não chegaria no Brasil. E, no contexto das narrativas negacionistas, o governo produziu a campanha "O Brasil não pode parar". O vídeo de 1'27" (um minuto e vinte e sete segundos) é composto por imagens de trabalhadoras e trabalhadores, assim como pessoas de classes baixas e em situação de vulnerabilidade social, que recebem apoio financeiro de programas sociais do governo federal. A narrativa da campanha é desenvolvida com um apelo para que a população brasileira continue trabalhando porque a economia e as pessoas mais carentes precisam de ajuda.

Ellsworth (2001, p. 13, grifo da autora) nos diz que "os filmes, assim como as cartas, os livros, os comerciais de televisão, são feitos para alguém. Eles visam e imaginam determinados públicos". Isto é, os produtos culturais são fabricados para uma recepção anteriormente imaginada. Tratando-se da campanha "O Brasil não pode parar", acreditamos que existem diferentes modos de endereçamento. Segundo a campanha publicitária do governo Bolsonaro, são "quase 40 milhões de trabalhadores autônomos", cuja força de trabalho é compreendida como essencial para a movimentação do mercado econômico interno. O texto do vídeo apresenta ainda as categorias profissionais elencadas como imprescindíveis para a manutenção da economia brasileira:

\footnotetext{
Ambulantes, engenheiros, feirantes, arquitetos, pedreiros e advogados, professores particulares e prestadores de serviço em geral. \#OBrasilNãoPodeParar". Para os comerciantes dos bairros, para os lojistas do Centro, para as empregadas domésticas, para milhões de brasileiros \#OBrasilNãoPodeParar (O BRASIL NÃO PODE PARAR, 2020).
}

A campanha produz a estratégia de endereçamento para diferentes categorias de trabalho. Entretanto, o discurso visual exibe uma preponderância de determinados sujeitos na imagem. Apesar da narrativa falar em engenheiros, advogados, arquitetos e professores particulares, profissões especializadas e que requerem formação universitária, as imagens que são veiculadas na peça publicitária retratam profissões autônomas que são culturalmente entendidas como subalternizadas na divisão social do trabalho: ambulantes, garis, empregadas 
domésticas, feirantes e pequenos comerciantes. Essa diferença entre o texto e a imagem demonstra a existência de camadas de endereçamento, visto que um único produto cultural pode "ter diferentes modos de endereçamento. Podem estar ocorrendo, de forma simultânea, múltiplos modos de endereçamento" (ELLSWORTH, 2001, p. 23).

Os múltiplos endereçamentos nos fazem entender que apesar do texto traçar uma determinada narrativa, as imagens utilizam códigos diversos. Isto é, o produto audiovisual ganha um caráter de múltiplos endereçamentos, cujas camadas devem ser interpretadas em nossa análise. A imagem das trabalhadoras e trabalhadores autônomos brasileiros é exposta na peça publicitária a partir de regimes de representação específicos. Hall (2016, p. 31) considera que "representação é uma parte essencial do processo pelo qual os significados são produzidos e compartilhados entre os membros de uma cultura", pois ela se concretiza no compartilhamento de códigos, linguagens e imagens. Isso quer dizer que toda representação parte de significados que estão construídos na cultura, ao mesmo tempo que forja as interpretações possíveis.

Vigoram na cultura brasileira os regimes de representação que marcam simbolicamente as posições dos sujeitos subalternizados, fazendo ver as marcações sociais desses sujeitos que são fixados nessas representações. Nesse sentido, a narrativa endereçada para "os quase 40 milhões de trabalhadores autônomos" possui um conjunto de imagens mentais que circula na cultura e se materializa em produtos culturais como a campanha "O Brasil não pode parar".

A visibilidade dada aos corpos de homens e mulheres negras na campanha nos alerta de que esse regime de representação se diferencia da injunção da visibilidade contemporânea, pois as pessoas negras são comumente estereotipadas em peças publicitárias, na mídia, na arte, nas ciências e em outros produtos culturais. Hall (2016, p. 190) alerta que "a estereotipagem enquanto prática de produção de significados é importante para a representação da diferença racial". Assim sendo, os estereótipos sobre as pessoas negras são retroalimentados em regimes de representação que aprisionam as imagens de pessoas negras (ver imagens 1, 2, 3 e 4). 
Imagens 1, 2, 3 e 4 - Frames da campanha "O Brasil não pode parar"
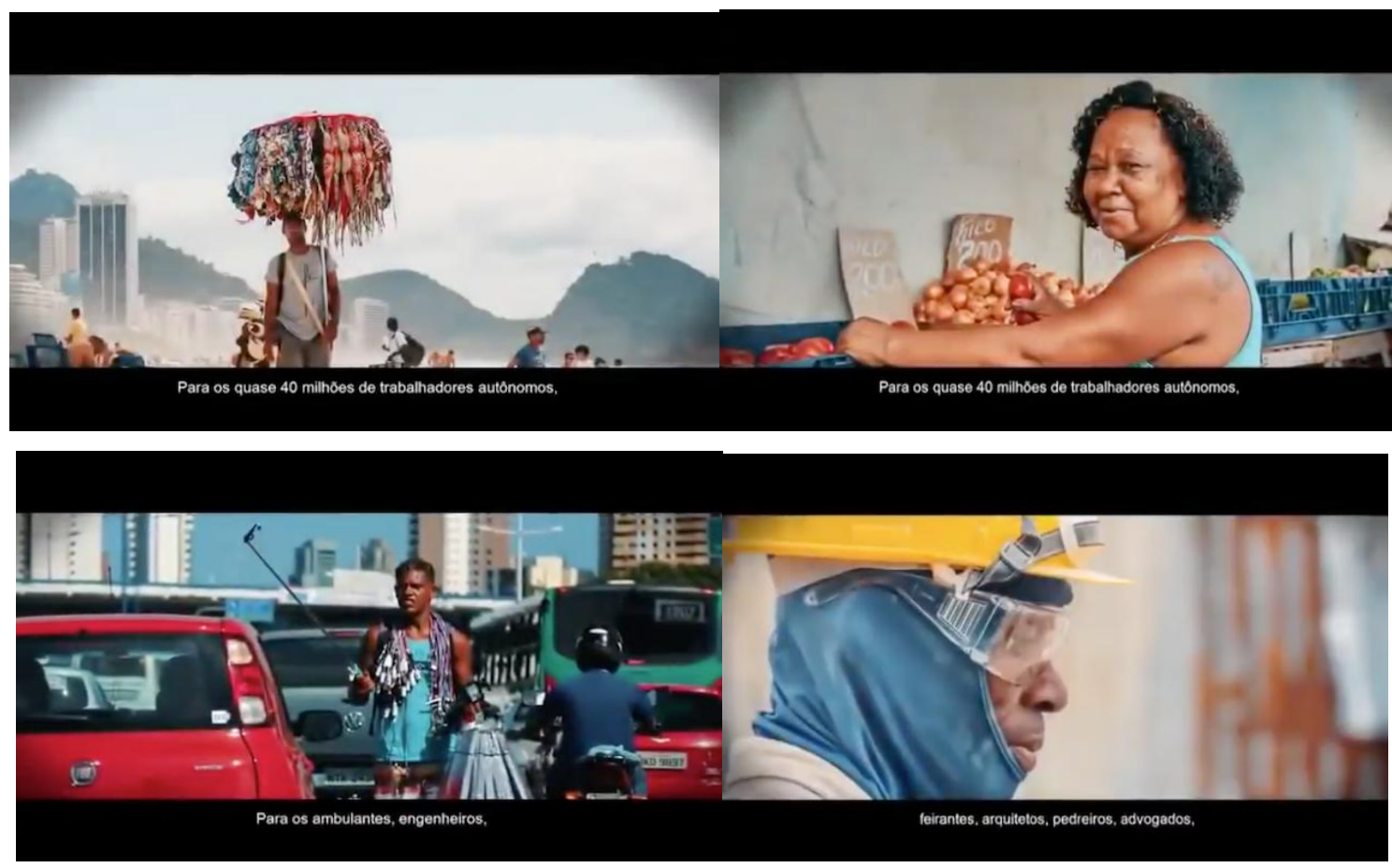

Fonte: Youtube.

Ao falar de trabalhadores autônomos, o regime de representação adotado pela campanha reitera uma determinada imagem estereotipada das trabalhadoras e trabalhadores brasileiros, pois essas representações, sem sombra de dúvida, reforçam o imaginário social acerca das atividades laborais realizadas por pessoas com menor nível de escolaridade, de cor de pele preta ou parda, por mulheres que são chefes de família, assim como de moradores de bairros periféricos. O trabalhador autônomo, na compreensão da campanha do governo federal brasileiro, é um sujeito social bem definido no que diz respeito às marcações de raça, classe e gênero.

Ellsworth (2001, p. 13) afirma que o endereçamento ocorre "num espaço que é social, psíquico, ou ambos, entre o texto do filme e os usos que o espectador faz dele". Nesse sentido, a campanha publicitária "O Brasil não pode parar" exerce uma sofisticada utilização dos regimes de representação racialmente marcados, visto que o vídeo visibiliza as pessoas negras como sujeitos hipossuficientes, carentes, pobres. Como afirma Gonzales (1984), na cultura brasileira as pessoas negras são representadas como subalternizadas. E as representações racistas e sexistas que vigoram no imaginário social brasileiro são identificadas na peça publicitária, visto que há uma reiteração desse lugar precário onde as pessoas negras são aprisionadas no campo da representação. 
Imagens 5 e 6 - Frames da campanha "O Brasil não pode parar"

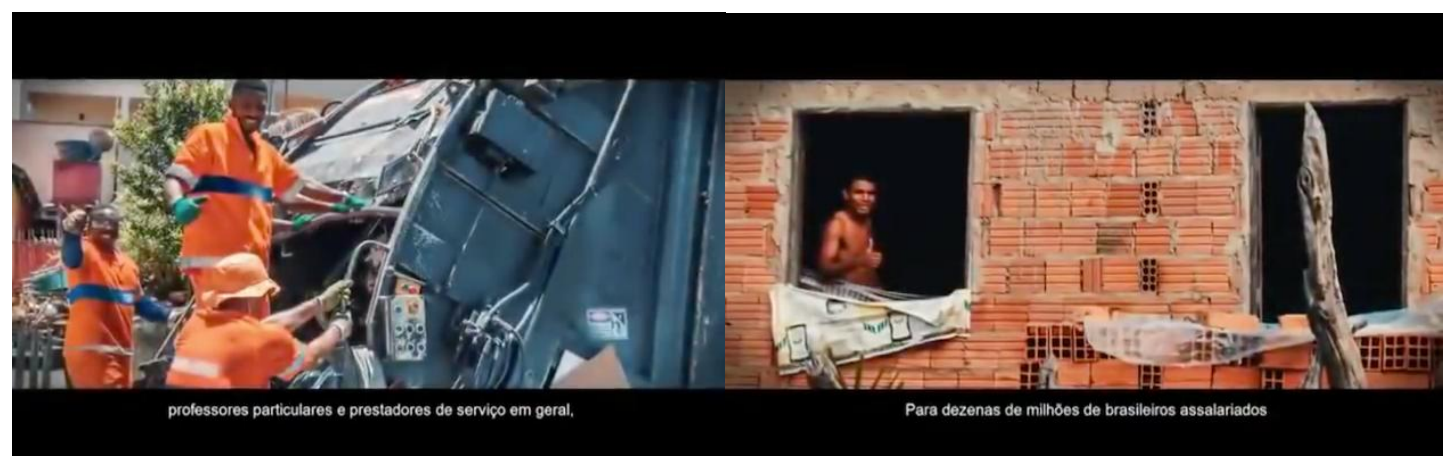

Fonte: Youtube.

$\mathrm{O}$ aprisionamento do sujeito negro como subalternizado nos remete às práticas do racismo cotidiano definido por Kilomba (2019, p. 224, grifo da autora), cujas encenações do colonialismo faz das pessoas negras uma figura "encarcerada em fantasias brancas do que ela deveria ser. Quando a campanha aprisiona as pessoas negras em figuras estereotipadas do trabalho subalternizado, um conjunto de códigos, valores e práticas racistas são expostas como reencenação do colonialismo. Reencena-se a dicotomia colonial da casa-grande e da senzala, cujo marcador racial define o lugar dos sujeitos na cultura.

$\mathrm{Na}$ cena colonial, por exemplo, a raça consagrou-se como elemento constitutivo do valor que é dado à vida. Ao "negro", coube o significado de um corpo transformado em mercadoria, em objeto de exploração escravagista (MBEMBE, 2018a). O corpo de pessoas negras tornou-se "mineral", "metal", "moeda", todos negros. Usando a metáfora do mineral, metal e da moeda, Mbembe explica como o trabalho forçado da escravidão subjetivou a pessoa negra, confinando-a como um objeto das rotinas do trabalho na colônia. Nesse tortuoso processo de subjetivação, a pessoa negra sofreu a perda de um lar (visto que foi raptado de seu território), a perda dos direitos sobre o próprio corpo e a perda de um estatuto político de sujeito. "Essa tripla perda equivale a uma dominação absoluta, uma alienação de nascença e uma morte social (que é expulsão fora da humanidade)" (MBEMBE, 2018a, p. 27).

No século XXI, as reencenações coloniais do racismo cotidiano revelam que as representações das pessoas negras no Brasil ainda são alimentadas pelo estereótipo da subalternidade e subserviência, reiterando códigos, linguagens e imagens que marcam as divisões sociais e a desigualdade racial. A campanha "O Brasil não pode parar" nos indica que os interesses da branquitude brasileira são postos no regime de representação, "devido ao fato 
de o sujeito branco não querer superar o passado" (KILOMBA, 2019, p. 226, grifo da autora), visto que a marcação racial define quem o governo brasileiro acredita que não pode parar de trabalhar. Sem sombra de dúvidas, esse discurso afirma que as pessoas negras compulsoriamente devem trabalhar.

“O Brasil não pode parar” é endereçada não apenas para que as pessoas negras mantenham as rotinas de trabalho, reiterando as lógicas de representação racistas e estereotipadas, mas satisfazem também o empresariado e as elites econômicas da base do governo Bolsonaro (BOLSONARO..., 2020). Afinal, o interesse dos empresários e da classe média é o de manutenção das lógicas de privilégio social (privilégio marcado historicamente pelo colonialismo). Logo, o trabalho de domésticas, garis, ambulantes e feirantes é compreendido como serviço essencial para o abastecimento das classes médias e altas. Não é à toa que determinados dirigentes conservadores de alguns estados brasileiros afirmaram que o trabalho doméstico é uma atividade essencial, colocando em risco a vida de trabalhadoras domésticas em diferentes cidades do país.

O contexto político e social do Brasil em 2020 fez emergir discursos que nos permitem identificar que o texto da narrativa da campanha "O Brasil não pode parar" é completamente compatível com os valores morais que regem o posicionamento político do governo Bolsonaro e de seus apoiadores, cuja manutenção de privilégios perpassa a proposta de exposição das populações mais vulneráveis ao vírus letal da covid-19. Safatle classificou as práticas negacionistas e desarrazoadas do governo brasileiro como práticas de um "estado suicidário", relembrando Paul Virilio. ${ }^{4}$ Em seu diagnóstico, Safatle (2020, não paginado) afirma:

O engenho não pode parar. Se para tanto alguns escravos morrerem, bem, ninguém vai realmente criar um drama por causa disso, não é mesmo? E o que afinal significa 5.000, 10.000 mortes se estamos falando em "garantir empregos", ou seja, em garantir que todos sejam massacrados e espoliados em ações sem sentido e sem fim enquanto trabalham nas condições as mais miseráveis e precárias possíveis?

A política negacionista em torno da letalidade do covid-9 no mundo transformou o Brasil em um dos epicentros da pandemia do novo coronavírus, em julho de 2020, cujo total de óbitos ultrapassou a marca de 80 mil pessoas (CORONAVÍRUS BRASIL, 2020). Esse cenário nos fez compreender que a existência dos discursos e argumentos contrários às práticas de isolamento social por parte do governo Bolsonaro construiu uma narrativa que demarca quais vidas são dignas de serem protegidas e quais vidas devem ser expostas ao vírus. Afinal, como

\footnotetext{
${ }^{4}$ Para Virilio (1993), Estado Suicidário é aquele que mina os recursos naturais e humanos em nome da primazia da técnica e da economia neoliberal, consolidando, assim, uma morte da própria estrutura estatal.
} 
destaca Safatle (2020, não paginado), “a população é apenas um suprimento descartável para que o processo de acumulação e concentração não parem sob hipótese alguma”.

A campanha "O Brasil não pode parar" demonstra que o Estado brasileiro endereçou a determinadas camadas da população um convite para manter o processo de crescimento econômico às custas das possíveis mortes provocadas pelo novo coronavírus. Nesse sentido, o governo Bolsonaro evidenciou a existência de estratégias que marcam as vidas que importam e as vidas que podem ser descartadas.

\section{A necropolítica e as vidas que importam}

Em maio de 2020, o presidente e fundador da empresa XP Investimentos, Guilherme Benchimol, afirmou em uma transmissão ao vivo realizada pelo jornal Folha de S. Paulo que o pico do novo coronavírus nas classes mais altas já havia passado.

Acompanhando um pouco os nossos números, eu diria que o Brasil está bem. Nossas curvas não estão tão exponenciais ainda, a gente vem conseguindo achatar. O pico da doença já passou quando a gente analisa a classe média, classe média alta. O desafio é que o Brasil é um país com muita comunidade, muita favela, o que acaba dificultando o processo todo (MOURA, 2020, não paginado).

Lamentavelmente, as previsões do investidor financeiro não se confirmaram. De acordo com o consórcio de veículos de imprensa formado por O Globo, Extra, G1, Folha de S. Paulo, Portal Uol e $O$ Estado de S. Paulo, que reúne informações das secretarias estaduais de Saúde, dois meses após a declaração de Benchimol, o país registrou mais de 90 mil óbitos por covid-19.

Preservar as vidas ou a economia? É impossível responder a essa pergunta sem considerar que os dois caminhos estão profundamente interligados. O IBGE demonstrou que a população brasileira mais afetada pela pandemia é pobre, negra e com pouco ou sem estudo e, consequentemente, residente em favelas e periferias. A Pesquisa Nacional por Amostra de Domicílio (Pnad Covid-19 ${ }^{5}$ ) destacou que $70 \%$ dos brasileiros que apresentaram sintomas de contaminação pelo coronavírus eram de cor preta ou parda (IBGE, [2020]). Segundo a Pesquisa Nacional por Amostra de Domicílios Contínua (Pnad Contínua), publicada em 2019, existem cerca de 6,5 milhões de trabalhadores domésticos no país, dos quais $92 \%$ são mulheres. O Brasil que não pode parar tem na raça negra e no gênero feminino a sua força motriz.

\footnotetext{
${ }^{5}$ Disponível em: https://covid19.ibge.gov.br/pnad-covid/.
} 
Mbembe (2018b) chama de necropolítica o fenômeno que consiste em controlar o corpo e a possibilidade de viver de determinados tipos de pessoas, selecionadas pelos critérios do poder estatal, levando em consideração o contexto social, territorial e, consequentemente, racial onde estão inseridas, não sendo necessário nenhum tipo de enfrentamento ou resistência, bastando que pertençam a essas fronteiras. Segundo Mbembe (2018b, p. 20), "a racionalidade de vida passa pela morte do outro, ou que a soberania consiste na vontade e capacidade de matar a fim de viver".

Em termos práticos, a máquina social afasta determinados indivíduos e seus semelhantes cada vez mais para a periferia, por não se enquadrarem no contexto social determinante. É como se a necropolítica operasse em preparo para a razão, o motivo da morte: morre-se por ser pobre, periférico, negro, independente da idade, porque também pressupõe que o futuro, a vida adulta, não será diferente daqueles que já ultrapassaram (ou sobreviveram) à infância. Esta política se estabelece a partir da submissão de certo grupo, que está sujeito ao controle de seu corpo por meio da vigilância e de uma política que pode chegar a utilizar o extermínio, para a efetivação da garantia de determinada ordem social. É quando o Estado Democrático de Direito não prioriza o cuidado e a manutenção da vida e sim a prática do genocídio.

O aumento dos casos de covid-19 nas periferias das grandes e pequenas cidades esboça uma performance do Estado que atinge desigualmente os desiguais, seja pela extinção de vidas negras pela violência e extermínio, seja pela omissão da assistência à saúde e à assistência social, os direitos sociais. Assim como as operações policiais nas comunidades periféricas não cessaram diante da pandemia, tampouco cumpriram a ordem do STF (STF MANTÉM..., 2020). A parcimônia e inexistência de políticas públicas eficazes de reparação da vida também são agentes que negam a humanidade de vidas negras. O Estado de Exceção já instaura modos de legislação, de existência, sendo ele a regra, o normal. A sua prática rotineira institui um modo próprio de assegurar ou não o direito à vida.

Para enfrentar o racismo no Brasil e impedir que produções como da campanha "O Brasil não pode parar" seja custeada com dinheiro público, sem gerência e responsabilidade, é necessário reconhecer a importância de mudanças na comunicação de massa no Brasil, tradicionalmente oligárquica e detentora de privilégios. Sodré (2015, p. 244) compreende a mídia brasileira como o intelectual coletivo de elites inclinadas ao capital financeiro e desvinculadas dos "ganhos democráticos [...] e (que) abrem mão de políticas nacionalmente 
soberanas".

A mídia, além de não se comprometer com os marcadores de raça e classe da população brasileira, também produz pequenas elites - definidas por Sodré como elites logotécnicas formadas por editorialistas, articulistas, editores, colunistas, âncoras de televisão, jornalistas especiais, etc. - principais zeladores da reprodução e disseminação do imaginário coletivo no que se refere à identidade e representação.

O imaginário racista veiculado pelas elites tradicionais pode ser hoje reproduzido logotecnicamente, de modo mais sutil e eficaz, pelo discurso midiático-popularesco, sem distância crítica do tecido da civilização tecnoeconômica, onde se acha incrustada a discriminação em todos os níveis (SODRÉ, 2015, p. 245).

Nega-se, midiática e socialmente, a existência do racismo, porém desta mesma forma perpetua-se a engrenagem que opera e permite que campanhas custeadas com dinheiro público tenham como personagens e atores sociais pessoas negras subalternizadas. Sodré (2015) classificou esse fenômeno como um problema epistemológico da comunicação, destacando a existência da negação do racismo e o silêncio midiático em torno do tema como uma das estratégias de fortalecimento do capital financeiro, onde a busca pelo lucro e o poder acabam por dizimar vidas negras.

\section{Considerações finais}

A análise da campanha "O Brasil não pode parar" evidenciou que os interesses econômicos da branquitude brasileira se materializaram na peça publicitária do governo Bolsonaro. Os regimes de representação adotados no vídeo reiteraram uma concepção estereotipada sobre as trabalhadoras e trabalhadores autônomos brasileiros, colocando em relevo reencenações coloniais que aprisionaram as pessoas negras em representações subservientes e submissas. A campanha destaca que o lugar cultural das pessoas negras é o da pobreza, da baixa escolaridade, da vulnerabilidade social, da mão de obra barata e sem qualificação.

Ao percebermos a existência de camadas de endereçamento capazes de produzir discursos para diferentes públicos - dos trabalhadores ao empresariado -, identificamos também que a peça atende não apenas ao apelo de uma retomada das atividades laborais de profissionais autônomos, em meio ao contexto da pandemia de covid-19, mas também aos interesses de dominação do empresariado, da branquitude e da classe média e alta brasileira. 
Esse complexo cenário se dá na exibição de corpos negros na peça publicitária, cujo discurso demarca a possibilidade de exposição das vidas negras à letalidade do novo coronavírus.

Ao afirmar que o Brasil não pode parar, a campanha induz as trabalhadoras e trabalhadores autônomos brasileiros a manter as rotinas laborais, mesmo com o indicativo de uma crise global na saúde pública, como alertado pela OMS no início de 2020. Levando em consideração que as condições sanitárias estão atreladas a indicadores sociais de classe, raça, gênero e geração, evidencia-se também que as pessoas negras, no Brasil, estão à margem do acesso aos serviços públicos de saúde, tornando-as mais propícias à vulnerabilidade social no atendimento da rede pública de saúde (KALCKMANN; SANTOS; BATISTA; CRUZ, 2007).

A peça publicitária aciona não apenas uma memória, mas o lugar que negros e pardos ocupam diante da crise sanitária. Reconhecida nacionalmente por meio de regimes de representação atrelados ao trabalho braçal e à resistência física, a população negra se vê diante de uma crise maximizada pela necessidade de sobrevivência que se acentua em períodos pandêmicos, uma vez que a própria valorização da vida não aparenta ser levada em consideração quando proposta a determinados grupos raciais, sociais e de gênero. Valer-se de discursos sobre a economia em momento crítico como o da pandemia de covid-19 é mexer em uma ferida histórica que indica que a população negra e pobre brasileira precisa trabalhar independente das circunstâncias. 


\section{Referências}

ALMEIDA, Silvio. Racismo estrutural. São Paulo: Sueli Carneiro: Pólen, 2019.

BENTO, Cida. Eugenia e coronavírus. Folha de S. Paulo, São Paulo, 24 de jun. 2020. Disponível em: https://www1.folha.uol.com.br/colunas/cida-bento/2020/06/eugenia-ecoronavirus.shtml. Acesso em: 14 jul. 2020.

BOLSONARO, Jair Messias. [Pronunciamento do presidente da República, Jair Bolsonaro]. 24 mar. 2020. Disponível em: https://www.youtube.com/watch?v=Vl_DYb-XaAE. Acesso em: 12 jun. 2020.

BOLSONARO vai ao STF com Guedes e empresários e diz que "economia é vida". Exame, 7 maio 2020. Economia. Disponível em: https://exame.com/economia/bolsonaro-diz-emreuniao-com-empresarios-que-teme-colapso-da-economia/. Acesso em: 12 jul. 2020.

BRASIL. Supremo Tribunal Federal. Medida cautelar na arguição de descumprimento de preceito fundamental 669 Distrito Federal. Recorrente: Rede Sustentabilidade. Recorrido: União. Min. Relator: Roberto Barroso. 31 de março de 2020. Disponível em: http://www.stf.jus.br/arquivo/cms/noticiaNoticiaStf/anexo/ADPF669cautelar.pdf. Acesso em: 12 jul. 2020.

CORONAVÍRUS BRASIL. Painel Coronavírus. Disponível em: https://covid.saude.gov.br. Acesso em: 21 jul. 2020.

ELLSWORTH, Elizabeth. Modos de endereçamento: uma coisa de cinema; uma coisa de educação. In: SILVA, Tomaz Tadeu da (org.). Nunca fomos humanos: nos rastros do sujeito. Belo Horizonte: Autêntica, 2001. p. 07-77.

GONZALES, Lélia. Racismo e sexismo na cultura brasileira. Revista Ciências Sociais Hoje, Brasília, Anpocs, p. 223-244, 1984. [No original, nome como Lélia Gonzalez].

HALL, Stuart. Cultura e representação. Rio de Janeiro: Ed. PUC-Rio: Apicuri, 2016.

KALCKMANN, Suzana; SANTOS, Claudete Gomes dos; BATISTA, Luís Eduardo; CRUZ, Vanessa Martins da. Racismo institucional: um desafio para a eqüidade no SUS? Saúde soc., São Paulo, v. 16, n. 2, p. 146-155, May/Aug. 2007. Disponível em: https://www.scielo.br/scielo.php?pid=S0104-

12902007000200014\&script=sci_abstract\&tlng=pt. Acesso em: 12 jun. 2020.

KILOMBA, Grada. Memórias da plantação - episódios de racismo cotidiano. Rio de Janeiro: Cabogó, 2019.

MAIORIA dos estados não divulga dados sobre cor de vítimas da Covid-19. Folha de S. Paulo, 21 jun. 2020. Disponível em: https://www1.folha.uol.com.br/equilibrioesaude/2020/06/maioria-dos-estados-nao-divulgadados-sobre-raca-de-vitimas-da-covid19.shtml?utm_source=twitter\&utm_medium=social\&utm_campaign=twfolha. Acesso em: 14 jul. 2020. 
MBEMBE, Achille. Crítica da razão negra. São Paulo: N-1 edições, 2018a.

MBEMBE, Achille. Necropolítica: biopoder, soberania, estado de exceção, política de morte. São Paulo: N-1 edições, 2018b.

MOURA, Julia. Pico de Covid-19 nas classes altas já passou; o desafio é que o Brasil tem muita favela, diz presidente da XP. Folha de S. Paulo, São Paulo, 5 maio 2020. Mercado. Disponível em: https://www1.folha.uol.com.br/mercado/2020/05/brasil-esta-indo-bem-nocontrole-do-coronavirus-e-pico-nas-classes-altas-ja-passou-diz-presidente-da-xp.shtml.

Acesso em: 12 maio 2020.

NITAHARA, Akemi. Negros são maioria entre desocupados e trabalhadores informais no país. Agência Brasil, Brasília, 13 nov. 2019. Disponível em: https://agenciabrasil.ebc.com.br/economia/noticia/2019-11/negros-sao-maioria-entredesocupados-e-trabalhadores-informais-no-pais. Acesso em: 10 jul. 2020.

O BRASIL não pode parar. Campanha do governo federal. 28 mar. 2020. Disponível em: https://www.youtube.com/watch?v=hQQZE7LQIGk. Acesso em: 10 jun. 2020.

O IBGE apoiando o combate à Covid-19. IBGE, [2020]. Disponível em: https://covid19.ibge.gov.br/pnad-covid/. Acesso em: 10 jul. 2020.

OMS diz que só isolamento controlará covid-19 e anuncia morte de crianças. UOL Notícias. 16 mar. 2020. Disponível em: https://noticias.uol.com.br/saude/ultimasnoticias/redacao/2020/03/16/oms-coronavirus.htm?cmpid=copiaecola. Acesso em: 12 jun. 2020

RIBEIRO, Ana Paula Goulart; MARTINS, Bruno Guimarães; ANTUNES, Elton. Linguagem, sentido e contexto: considerações sobre comunicação e história. Revista Famecos (Online). Porto Alegre, v. 24, n. 3, set./dez. 2017. Disponível em: https://revistaseletronicas.pucrs.br/ojs/index.php/revistafamecos/article/view/27047. Acesso em: 10 jun. 2020.

SAFATLE, Vladimir. Bem-vindo ao estado suicidário. Disponível em: https://www.n1edicoes.org/textos/23. Acesso em: 04 ago. 2020.

SODRÉ, Muniz. Claros e escuros: identidade, povo e mídia no Brasil. Petrópolis, RJ: Vozes, 2015.

SOUZA JÚNIOR, José Ronaldo de C.; CAVALCANTI, Marco A. F. H.; LEVY, Paulo Mansur; CARVALHO, Leonardo Mello de; MORAES, Marcelo Lima de; GARCIA, Pedro Mendes. Atividade econômica: revisão das previsões de crescimento. IPEA, 9 jun. 2020. Disponível em: https://www.ipea.gov.br/cartadeconjuntura/index.php/tag/previsoesmacroeconomicas/. Acesso em: 27 jun. 2020.

STF MANTÉM proibição de ações policiais em favelas do RJ durante a pandemia de Covid. G1, 5 ago. 2020. Disponível em: https://g1.globo.com/rj/rio-de-janeiro/noticia/2020/08/05/stfmantem-proibicao-de-acoes-policiais-em-favelas-do-rj-durante-a-pandemia-de-covid.ghtml.

Acesso em: 14 ago. 2020. 
VIRILIO, Paul. El Estado suicida. In: La inseguridad del territorio. Buenos Aires: La Marca, 1993.

VITAL, Danilo. Em liminar, ministro Barroso pró́be campanha "O Brasil não pode parar". Consultor Jurídico, 31 mar. 2020. Disponível em: https://www.conjur.com.br/2020-mar31/liminar-barroso-proibe-campanha-brasil-nao-parar. Acesso em: 12 jun. 2020.

Submetido em 24.09.2020

Aprovado em 09.11.2020 